\title{
Performance Analysis of Oversampled OFDM over PLC Network
}

\author{
Abdelmounim Hmamou ${ }^{1}$, Mohammed El Ghzaoui², Jaouad Foshi¹, Jamal Mestoui², \\ Abdlhalim El Basset ${ }^{1}$, Sudipta Das ${ }^{4}$ \\ 1 TTI Team, ERTTI Laboratory, Moulay Ismail University of Meknes, Morocco \\ 2 Sidi Mohamed Ben Abdellah University, Faculty of Sciences, Fes, Morocco \\ ${ }^{3}$ LSSC, Faculty of Sciences and Technology, Sidi Mohmed ben Abdellah University, Morocco \\ ${ }^{4}$ Department of ECE, IMPS College of Engineering and Technology, W.B., India
}

(Received 15 January 2021; revised manuscript received 14 June 2021; published online 25 June 2021)

\begin{abstract}
A solution that today interests a good number of industrialists consists in using the most dense and ubiquitous network: the electricity network. Communication over energy line, commonly known as PLC (Power Line Communications), makes it possible to consider a completely different type of electrical local loop. The main advantage of such a network relies to the ubiquity of the infrastructure, both inside and outside buildings, thus, making it possible to considerably limit the costs of network deployment. One of the options chosen to increase throughput on the PLC networks is the use of OFDM (Orthogonal Frequency Division Multiplexing). This modulation allows optimal use of the frequency band, while providing very good resistance to interference. However, one of the problems with these modulations is the cardinal sinus frequency response of the transmitter and receiver filters. Thus, the idea of using filters other than rectangular filters can be considered to overcome this problem. In this direction, oversampled OFDM modulation has been proposed in this work. The main objective of this paper is to analyze the performance of the oversampled OFDM modulation in terms of the PSD (Power Spectral Density) and the BER (bit error rate). From simulation, we can conclude that the performance of the oversampled OFDM technique surpasses the conventional OFDM in terms of BER and PSD.
\end{abstract}

Keywords: PLC, OFDM, Oversampled OFDM, DSP, BER.

DOI: 10.21272/jnep.13(3).03035

PACS number: 07.05.Tp

\section{INTRODUCTION}

Communications by PLC (Power Line Communication) are currently experiencing a boom, as they offer the possibility of building a very high-speed home local network using the existing electrical infrastructure of buildings [1-3]. However, the PLC transmission channel is a difficult environment, as the different branches of the network produce multipaths similar to the propagation conditions of wireless networks $[4,5]$. Current PLC modems use the lower end of the spectrum up to a maximum frequency of around $100 \mathrm{MHz}$. These severe constraints of the channel have motivated many researchers around the world to carry out quality research both concerning the characterization and the modeling of the channel made up of the power line as well as the definition of digital communication chains making it possible to limit the undesirable effects of the main disturbances of the PLC channel. Particularly the effects of multipath propagation and stationary noise have been compensated by the use of transmission techniques such as OFDM (Orthogonal Frequency Division Multiplexing).

OFDM modulation has been used in several standards, particularly in the transmission of information over power lines. Moreover, OFDM was chosen by the Homeplug committee [6,7], which means that all equipment bearing this certification works with this modulation. Indeed, the OFDM technique consists in dividing the channel into multiple sub-channels. The carrier itself is therefore divided into sub-carriers by the transmitter. It is up to the receiver to reconstitute the communication, from this different information. The frequency used therefore becomes a sub-frequency multiplexing (Division
Multiplexing). To avoid interference, the sub-carriers are processed by a Fourier transformation called Fast Fourier Transform (FFT). This algorithm samples the different subcarriers, so that the level corresponding to the information on one of them corresponds to zero levels on the others [8]. OFDM allows optimal use of the frequency band, while providing very good resistance to interference [9-11]. This is because disturbances may affect only one or a few subcarriers, not the entire transmission. In addition, the problem of multi-paths is reduced, by introducing redundancy codes. This technique has been used in several standards, notably 4G [12] and 5G [13].

The classical OFDM can thus be seen as an orthogonal family with critical density. In this case, the BalianLaw theorem indicates that it is not possible to use filters that are both well localized in time and in frequency. To obtain filters having better properties than the rectangular function, it is therefore necessary to study the modulations corresponding to Weyl-Heisenberg families with sub-critical density. This corresponds to lengthening the symbol time (or equivalent, increasing the inter-porous space), as proposed in [14]. A first generalization of classical OFDM can be carried out by seeking to obtain orthogonal multi-carrier modulations by sampling as in the case of oversampled OFDM modulation. It is this last modulation that we will use it for the transmission optimization on the PLC channels. This modulation will be studied in terms of DSP and BER.

\section{OVERSAMPLED OFDM}

Given the advantages and limitations of conventional OFDM and OFDM / CP, the question arises whether it 
is possible to find another kind of OFDM modulation with better properties. One of the problems posed by these modulations comes from the cardinal sine frequency response of the transmit and receive filters, so, the idea of using filters other than rectangular filters can be a good solution. In fact, both classical OFDM and OFDM/CP can be studied within the framework of the Weyl-Heisenberg families.

\subsection{Digital Oversampled OFDM}

The purpose of the multi-carrier transmitter is to distribute information in time and frequency. This transmission technique makes it possible to isolate areas of the time-frequency plane affected differently by the mobile radio channel. This is particularly useful in the case of dynamic power allocation, the choice of the number of bits per symbol, or the configuration of the errorcorrecting encoder. Here we present an equivalent multi-carrier transmission chain in baseband.

Let be a binary information source that delivers words of $n_{b}$ bits. To each word is associated a complex number $c_{m, n} \in C_{b}$, called symbol with $(m, n) \in I$ and $I \subset$ $Z^{2}$. The $C_{b}$ set constitutes a constellation, defined as Card $\left\{C_{b}\right\}=2^{b}$ (e.g., Quadrature Amplitude modulation at $2^{b}$ states). Assuming an appropriate coding process, the symbols are considered independent and identically distributed. The transmitter of the oversampled OFDM is represented in Fig. 1.

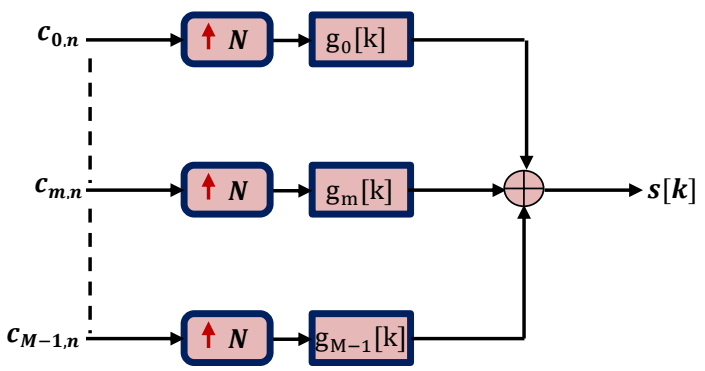

Fig. 1 -Discrete time oversampled OFDM transmitter with $I=\{0, \ldots, M-1\} \times Z$ and an oversampling factor $N / M$

To obtain a digital modulation system from the mathematical expressions of the oversampled signal, one can either proceed by simple sampling, or directly use the theory of Weyl-Heisenberg families. The link between continuous-time and discrete-time formulations can be made by choosing a sampling period such that the density is written $d=N / N^{\prime}$. Therefore $N^{\prime}>N$, so that in order to transmit $N$ data symbols $N^{\prime}$ samples are necessary, we will therefore speak of an oversampled OFDM system. Then the discrete signal of the oversampled OFDM is expressed in the form:

$x[m]=\sum_{i} \sum_{k=1}^{N}\left\{c_{i, k} g(m-i J N) \exp \left(j 2 \pi \frac{k}{N}\left(m-\frac{D}{2}\right)\right)\right\}$,

where $g[k]$ represents the prototype filter which will be assumed to have a finite impulse response (FIR) of length $L, D$ is a parameter linked to the processing delay introduced by the system. In the orthogonal case $D=L-1$.

The demodulation equations are obtained by developing the complex scalar product in a discrete way:

$$
\hat{c}_{k, i}=\left\langle g_{k, i}, x\right\rangle_{\text {discret }}=\sum_{-\infty}^{+\infty} g_{k, i}^{*}[m] x[k],
$$

where

$$
g_{k, i}[m]=g\left(m-i N^{\prime}\right) e^{j 2 \pi \frac{k}{N}\left(m-\frac{D}{2}\right)} .
$$

At the receiver, in the case of an ideal transmission channel, without noise, the symbols $c_{m, n}$ can be perfectly reconstructed when the family $\left\{\operatorname{g}_{m, n}\right\}(m, n) \in I$ forms a Riesz basis of the space it generates. In this case, the dual base denoted as $\left\{\breve{g}_{m, n}[l]\right\}(m, n) \in I$ is such that $\forall(m, n) \in I$, we have

$$
\check{g}_{m, n}[l]=\breve{g}\left(l-n N^{\prime}\right) e^{j 2 \pi \frac{m}{N}\left(l-\frac{D}{2}\right)} .
$$

The block diagram of the oversampled OFDM receiver is presented in Fig. 2.

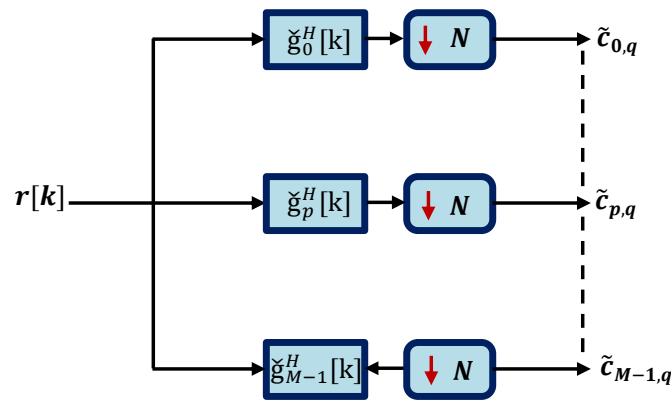

Fig. 2 -Discrete time oversampled OFDM receiver with $I=\{0, \ldots, M-1\} \times Z$ and an oversampling factor $N / M$

In the discrete-time version, the notion of oversampling appears explicitly, and we speak of oversampled OFDM [14]. However, a risk of confusion is always possible because the term OFDM oversampled is also used for OFDM systems where the modulated signal is obtained for $N=N^{\prime}$. From this, it is possible to explain more clearly why we speak of over-sampled OFDM. Indeed, we observe that the TB JN sampling period is smaller than the critical $\mathrm{TB} / \mathrm{N}$ sampling period. As a result, signal samples are sent by symbol time (whereas in the case of OFDM it is only transmitted samples). This signal is therefore oversampled compared to the signal from conventional OFDM. But it is important to note that the signal is not an OFDM signal that has been oversampled with an oversampling ratio $\mathrm{J}$ or by some integer ratio, as is the case in [15].

\subsection{Time-Frequency Localization}

For a discreet signal $x$, we use discreet localization noted $\zeta$

$$
\zeta(x)=\frac{1}{\sqrt{4 m_{2}(x) M_{2}(x)}},
$$

where the quantity $m_{2}(x)$ and $M_{2}(x)$ are the time and frequency moments, respectively.

\subsection{Minimization of Out-of-Band Energy}

The second criterion that we consider is that of minimization of the weighted norm of the error, noted $E(v)$, in frequency. For a weighting function, denoted $W(v)$, the objective function described in [16] is written:

$$
J_{W}=\int_{0}^{\frac{1}{2}} W(v)\|E(v)\|^{2} d v .
$$


In the present case we choose a constant weighting function in each interval defining the bands, low pass and high pass, of the prototype low pass filter. For a prototype filter $p$, whose Fourier transform is $P(v)$, the function to be minimized is then written by:

$$
J_{\rho, \alpha}=\rho \int_{0}^{f_{\alpha}}|1-P(v)|^{2} d v+(1-\rho) \int_{f_{s}}^{\frac{1}{2}}|P(v)|^{2} d v,
$$

where $\alpha$ and $\rho$ are two real numbers between 0 and 1 , with $\rho$ the weighting parameter and $\alpha$ the roll-off factor, which partly determines the limits of the pass bands, $f_{p}$, and attenuated, $f_{s}$. Thus, for a system comprising $2 M$ carriers (or sub-bands), we have:

$$
f_{p}=(1-\rho) \frac{1}{4 M} \text { and } f_{s}=(1+\rho) \frac{1}{4 M} .
$$

As the effect of the perfect reconstruction constraint favors good behavior in the bandwidth, we choose to take $\rho=1$.

\subsection{Power Spectral Density of the Oversampled OFDM Signal}

The oversampled OFDM modulation emission filter has interesting spectral properties [14] (good frequency localization for example). Consequently, an emission spectrum having significant out-of-band attenuations, therefore it has interesting advantages for transmissions via a PLC channel. The Square Root of Raised Cosine (SRRC) Raised Cosine Filter is a widely used reference filter in digital communications. For a transmission at the rate $F_{0}=1 / T B$, the frequency expression of the SRRC function is given by [14]

$$
R_{c}(v)=\left\{\begin{array}{lc}
\frac{1}{\sqrt{F_{0}}} & |v| \leq(1-\alpha) \frac{F_{0}}{2}, \\
\frac{1}{\sqrt{F_{0}}} \cos \left(\frac{\pi}{2 \alpha}\left(\frac{|v|}{F_{0}}-\frac{1-\alpha}{2}\right)\right) & (1-\alpha) \frac{F_{0}}{2} \leq|v| \leq(1+\alpha) \frac{F_{0}}{2}, \\
0 & (1+\alpha) \frac{F_{0}}{2}<|v|
\end{array}\right.
$$

where $\alpha$ is the roll-off factor $(0 \leq \alpha \leq 1)$.

In Fig. 3, the frequency response of the SRRC filter will be given with a roll-off equal to 0.5, sampled for 2048 carriers.

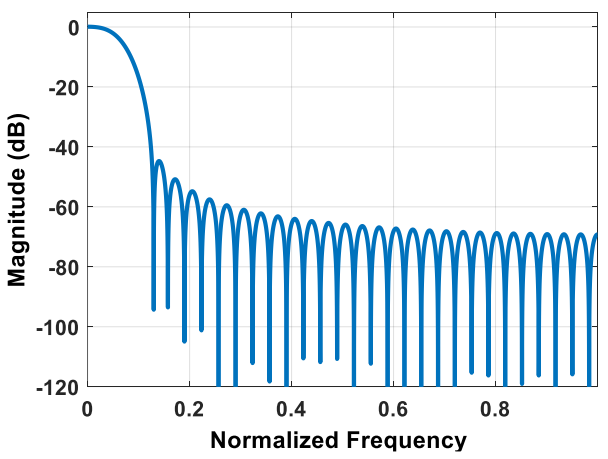

Fig. 3 - Magnitude response (dB) of SRRC filter with a roll-off $\alpha=0.5$

To avoid interference phenomena between different applications, current standards provide for very strong constraints on the signal emission spectra. In this context, signals having a well-confined emission spectrum and having significant out-of-band attenuations then have interesting advantages. The study of Power Spec- tral Density (PSD) then becomes a key point for this type of transmission such as PLC based transmissions. The prototype filter is the focal point of these waveform modulations. Indeed, these modulations were mainly introduced in order to be able to use waveforms other than rectangular because the latter has uninteresting spectral properties (poor frequency localization for example). For the oversampled OFDM, the expression of the DSP is:

$$
\Phi(f)=\frac{\sigma_{c}^{2}}{T_{B}} \sum_{k=1}^{N}\left|G\left(f-f_{k}\right)\right|^{2} .
$$

Fig. 4 shows the oversampled OFDM DSP using an SRRC filter with a (roll-off) factor equal to 0.5 (the choice of the roll-off of the SRRC filter is also directly related to the time-frequency structure of modulation), for 2048 carriers and of length 2048. We note first of all that the phenomena of power fluctuation in the signal band do not exist in oversampled OFDM.

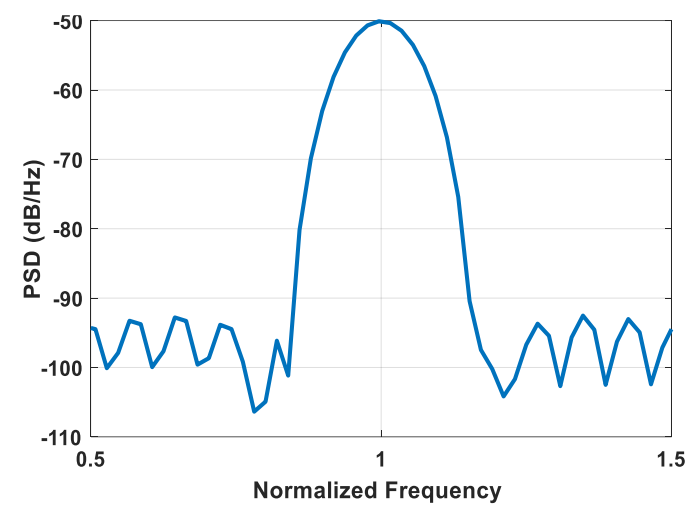

Fig. 4-PSD of oversampled OFDM estimated with Welch method for 4048 subcarriers

In the following we study the performance of oversampled OFDM systems in terms of BER through a PLC channel. To do that we should firstly give the PLC channel transfer. In Fig. 5, a typical PLC channel is represented. It is clear from this figure that the PLC channel is a selective channel with several notches. This channel will be used to determine the performance of the proposed system.

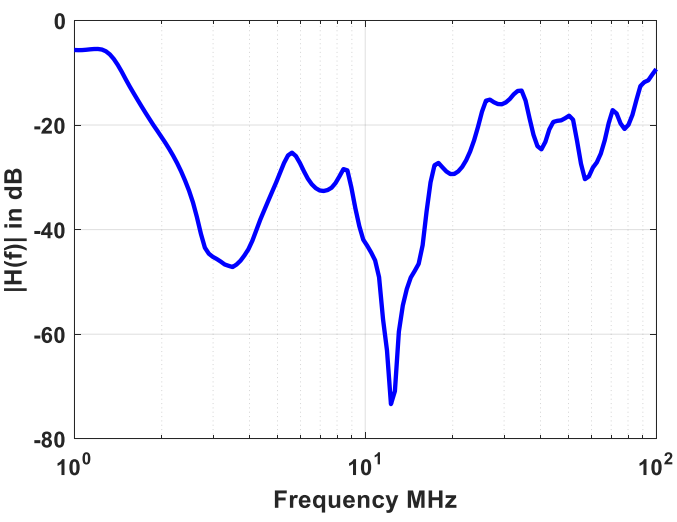

Fig. 5 - Transfer function of the PLC channel

We try to minimize the average BER of the system for a given rate and an imposed mask of DSP. In fact, to define the quality of a digital transmission chain, the BER is used as a metric, depending on the type of modulation used. There is a relationship between BER and 
signal to noise ratio (SNR). To compare the performances of the two systems, we choose to plot at constant bandwidth the variations of BER as a function of SNR. The curves in Fig. 6 represent the variation of BER as a function of SNR for conventional OFDM and oversampled OFDM.

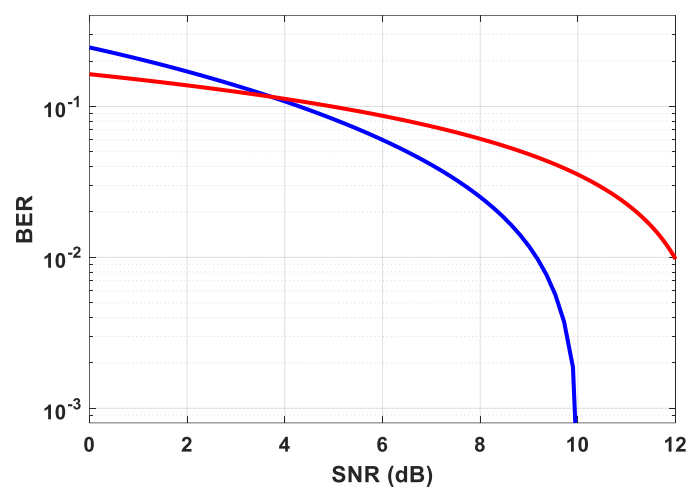

Fig. 6 - BER of oversampled OFDM versus conventional OFDM over PLC channel $\left(N=2048, T_{g}=6 \mu \mathrm{s}, \tau_{\max }=4 \mu \mathrm{s}\right)$

We move now to see the influence of symbol length on the performance of the proposed system. The BER versus frequency of the proposed system is depicted in Fig. 7. We noted from this figure that the shorter the symbol duration, the more sensitive the system is to the temporal selectivity of the channel. On the contrary, when the symbols duration is longer, the channel becomes plat with less interferences.

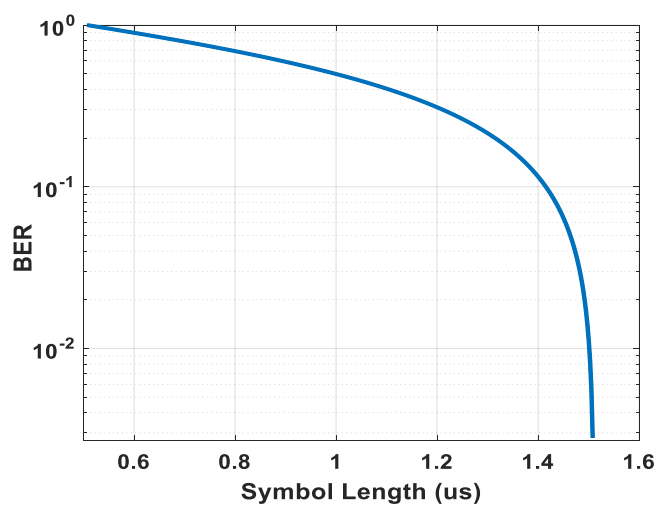

Fig. 7 - The BER versus symbol duration of oversampled OFDM

\section{CONCLUSIONS}

This paper has confirmed one of the main characteristics of waveform modulations, namely an excellent appearance of the power spectral density. We have optimized high-speed data transmission over such a channel. Thus, it was possible to achieve a BER of $10^{-4}$ without coding. Oversampled OFDM modulation appears to be more robust against ISIs caused by multipath propagation phenomena.

\section{REFERENCES}

1. M. Tlich, A. Zeddam, F. Moulin et al., IEEE Trans. Power Deliv. 23 No 3, 1392 (2008)

2. J. Le, C. Wang, W. Zhou, et al. Prot. Contr. Mod Power Syst. 2, 14 (2017)

3. A. Hmamou, M. El Ghzaoui, J. Foshi, J. Mestoui, The 4th International Conference on Big Data and Internet of Things, ID 33 (2019).

4. J. Francisco, S. Pacheco, P.J. Sotorrío-Ruiz, et al., IEEE Trans. Instrum. Measurement 63 No 9, 2215 (2014).

5. S. Moya, M. Hadad, M. Funes, et al., IET Commun. 10 No 13 , 1605 (2016).

6. J. Belkadid, A. Benbassou, M. El Ghzaoui, International Journal on Communications Antenna and Propagation (IRECAP) 3 No 5, 267 (2013).

7. Freddy A. Pinto-Benel, Fernando Cruz-Roldán, Journal of the Franklin Institute 357 No 11, 7211 (2020).

8. R. Vallet, K.H. Taieb, Wireless Personnal Communications 2 No 1, 97 (1995).

9. J. Mestoui, M. El Ghzaoui, A. Hmamou, J. Foshi, Procedia Comput. Sci. 151, 1016 (2019).

10. Y. Li, M. Zhang, W. Zhu, M. Cheng, C. Zhou, Y. Wu, China Commun. 17 No 1, 151 (2020).

11. H. Rui, L. Xiaoping, C. Shidong, C. Xiangqun, L. Jun, C. Peng, 2018 IEEE 18th International Conference on Communication Technology (ICCT), 936 (Chongqing: 2018).

12. Mordecai F. Raji, et al., Scientific Program. 2020, 3204695 (2020).

13. M. El Ghzaoui, A. Hmamou, J. Foshi, J. Mestoui, J. Circuit. Syst. Comput. 29 No 16, 2050257 (2020).

14. A. Skrzypczak, P. Siohan, J.P. Javaudin, International Symposium on PowerLine Communications and Its Applications (ISPLC) (2007)

15. P. Siohan, C. Siclet, N. Lacaille, IEEE Trans. Signal Proc. 50 1170 (2002).

16. R. Bregovié, T. SaramÄaki, IEEE ISCAS'01, 33 (Sidney: Australia: 2001).

\section{Аналіз ефективності передискретизованії OFDM через мережу PLC}

Abdelmounim Hmamou ${ }^{1}$, Mohammed El Ghzaoui², Jaouad Foshi¹, Jamal Mestoui², Abdlhalim El Basset ${ }^{1}$, Sudipta Das ${ }^{4}$

${ }^{1}$ TTI Team, ERTTI Laboratory, Moulay Ismail University of Meknes, Morocco

${ }^{2}$ Faculty of Sciences, Sidi Mohamed Ben Abdellah University, Fes, Morocco

${ }^{3}$ LSSC, Faculty of Sciences and Technology, Sidi Mohmed Ben Abdellah University, Morocco

${ }^{4}$ Department of ECE, IMPS College of Engineering and Technology, W.B., India

Рішення, яке сьогодні цікавить велику кількість промисловців, полягає у використанні найщільнішої та найпоширенішої мережі - електричної мережі. Зв'язок по електричній лінії, широко відомий як PLC (power line communications), дозволяе розглянути зовсім інший тип електричної локальної 
петлі. Основна перевага такої мережі полягае в повсюдному поширенні ії інфраструктури як всередині, так і зовні будівель, що дозволяе значно обмежити витрати на розгортання мережі. Одним із варіантів, обраних для збільшення пропускної здатності в мережах PLC, е використання OFDM (orthogonal frequency division multiplexing). Ця модуляція дозволяе оптимально використовувати смугу частот, забезпечуючи при цьому дуже гарний опір перешкодам. Однак одніею з проблем таких модуляцій е кардинальна синусоїдальна частотна характеристика фільтрів передавача і приймача. Таким чином, ідея використання інших фільтрів, крім прямокутних, може розглядатися для подолання даної проблеми. У цьому напрямку в роботі пропонуеться передискретизована модуляція OFDM. Основною метою роботи є аналіз ефективності передискретизованої модуляції OFDM з точки зору PSD (power spectral density) та BER (bit error rate). 3 моделювання можна зробити висновок, що ефективність передискретизованої методики OFDM перевершуе звичайну OFDM з точки зору BER та PSD.

Ключові слова: PLC, OFDM, Передискретизована OFDM, DSP, BER. 